\title{
A laparoscopic study investigating 3D vs 2D imaging systems using a pelvitrainer model with experts, non-experts, and students
}

Tibor Andrea Zwimpfer ${ }^{1 *}$, Dominik Lacher ${ }^{2}$, Bernhard Fellmann-Fischer ${ }^{1}$ and Michael Mueller ${ }^{3}$

\begin{abstract}
Background: Vision is an essential element of laparoscopic surgery that defines the outcome of an operation in regards to time, mistakes and precision. A 3-dimensional (3D) perspective may improve vision during an operation. Therefore, this study was designed to compare 3D versus 2-dimensional (2D) perspectives using a pelvitrainer model.

Methods: Fifty candidates were divided into 3 categories based on different experience levels. The candidates were randomised into two groups, with each group performing the same 4 standardised tasks. Group A approached the tasks first with 3D high definition and in a second turn with 2D high definition. Group B carried out the tasks with the systems in reverse order. Task completion time and the number of mistakes made for each task were recorded. After completing the tasks, participants answered questions concerning the two systems.

Results: Group A was, on average, 20\% faster at all four tasks and made approximately 18\% fewer mistakes in two of the tasks in comparison to group B. The experts significantly benefited from the 3D system in terms of accuracy compared to non-experts and students. The students demonstrated a significantly greater benefit from the 3D system when performing non-linear, continuous movements. Loss of concentration occurred at the same rate for subjects using the 2D and 3D systems. Nausea and dizziness were reported only when working with the 3D system. 91\% found the 3D system advantageous for accomplishing the tasks.

Conclusions: Irrespective of experience level, 3D laparoscopy shows advantages in saving time, increasing accuracy and reducing mistakes. These benefits were also accompanied by subjective advantages that were noted by the participants. However, the more complex the task, the less significant the benefit of the 3D system and some people feel handicapped by the eyewear.
\end{abstract}

Keywords: 3D laparoscopy, 2D laparoscopy, Pelvitrainer, Standardised tasks

\footnotetext{
* Correspondence: tibor.zwimpfer@unibas.ch

${ }^{1}$ University Hospital Basel, Gynecological Clinic, Basel, Switzerland

Full list of author information is available at the end of the article
}

C C The Author(s). 2020 Open Access This article is licensed under a Creative Commons Attribution 4.0 International License, which permits use, sharing, adaptation, distribution and reproduction in any medium or format, as long as you give appropriate credit to the original author(s) and the source, provide a link to the Creative Commons licence, and indicate if changes were made. The images or other third party material in this article are included in the article's Creative Commons licence, unless indicated otherwise in a credit line to the material. If material is not included in the article's Creative Commons licence and your intended use is not permitted by statutory regulation or exceeds the permitted use, you will need to obtain permission directly from the copyright holder. To view a copy of this licence, visit http://creativecommons.org/licenses/by/4.0/. The Creative Commons Public Domain Dedication waiver (http://creativecommons.org/publicdomain/zero/1.0/) applies to the data made available in this article, unless otherwise stated in a credit line to the data. 


\section{Background}

Laparoscopic surgery is a common procedure that offers numerous advantages including a reduction in postoperative infection and blood loss, better cosmetic outcomes and shorter hospital stays [1-3]. However, there are some disadvantages in comparison to laparotomies. For example, surgeons experience fatigue more quickly, there are only four degrees of freedom and operations take longer $[4,5]$. With the help of 3-dimensional (3D) visualizations it is possible to shorten the operation time and achieve cost reductions [6]. Additionally, higher precision and fewer mistakes are made [7-9]. To date, there have been a number of other studies investigating the advantages and disadvantages of using a 3D imaging system for conventional laparoscopy (LSC) [7, 10-12]. Various study designs have been used, and most compare two different groups using either a 3D or 2- dimensional (2D) system for exercises on a pelvitrainer, or in vivo [9-12]. In our study, an objective comparison of 3D vs 2D LSC was carried out using a pelvitrainer with a variety of standardised exercises performed by laparoscopic experts, non-experts and medical students. The exercises tested surgical competence regarding time, precision and mistakes. In addition, a subjective evaluation in the form of a questionnaire was used to assess the systems. Our study hypothesis tests the idea that the application of the 3D system reduces operation time and mistakes, and optimises precision.

\section{Methods}

\section{Study population}

In total, 60 participants were tested and 50 measurements were used. The first 4 participants were not included because the study design was changed to

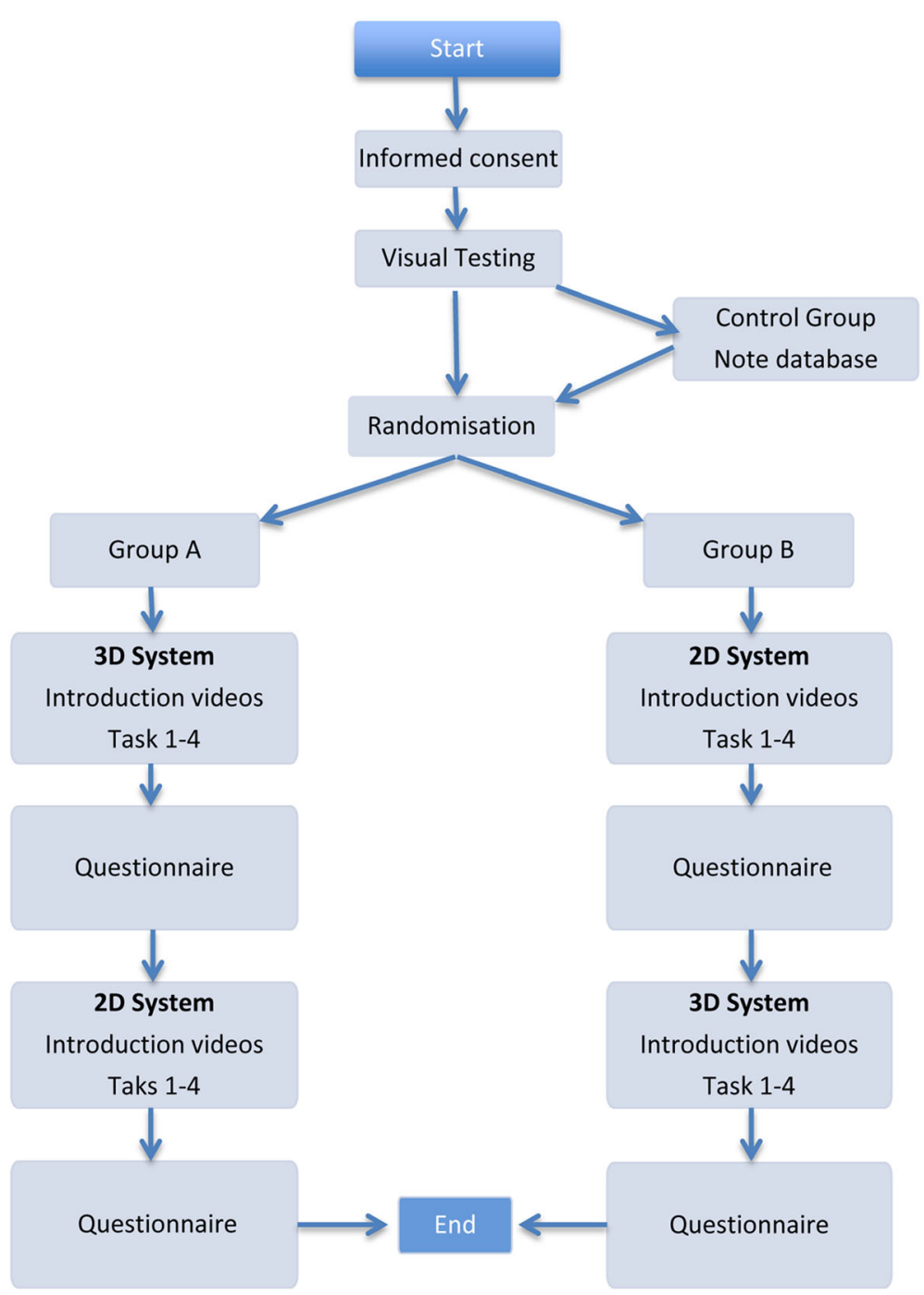

Fig. 1 Flow chart: Measurement procedure 
incorporate a dynamic rather than static camera movement. Two of the study participants were stereoblind according to the Lang stereo test and therefore excluded. Four candidates aborted their trials prematurely as they were interrupted due to emergency operations.

The used measurements were from fifteen experts with an average age of 48.7 years (who had conducted more than 50 laparoscopic operations per year for at least 5 years) recruited at the gynaecological laparoscopic course in Davos, Switzerland. Additionally, we selected 15 non-experts with an average age of 34.7 years (who had performed more than 10 but less than 50 laparoscopic operations), who were assistant physicians at the University of Berne and 20 medical students with an average age of 24.9 years (no experience in LSC) from the University of Berne. All participants had to give their consent to participate in this study and waive any claims. The anonymisation of personal data was guaranteed. The project is not defined as a research project according to Human Research Act Art. 2; therefore, an IRB approval and written consent is not needed.

\section{Study design}

All participants performed four standardised exercises. They were randomly assigned to one of two groups. The group composition was structured as follows: Group A includes 11 students, 11 non-experts and 6 experts. Group B includes 9 students, 4 non experts and 9 experts. Group A first performed the standardised exercises with the 3D system and then with 2D system. Group B carried out the exercises in the reverse systems order Fig. 1. The systems used were 3D HD (high definition) and 2D HD systems by Karl Storz (Karl Storz SE \& Co., Tuttlingen, Germany). Time, precision and mistakes were recorded during each subject's performance. Once participants had completed all of the exercises they were given a questionnaire that asked about their experience with both systems.

\section{Visual test}

The inclusion of stereo-blind people would have distorted the main study results. Therefore, participants with stereo-blindness who took part in the study were marked as a reference group and are to be evaluated separately in the analysis. Verification of stereoblindness was accomplished using the Lang stereo test. Because of the small number in this reference group (2 study participants), a separate statistical analysis using this group was not performed.

\section{Instrument set-up}

All exercises were carried out on two pelvitrainers constructed such that they correlated with the area surrounding the arcuate line of Douglas. Two endoscopy towers were identically set up, and both systems were
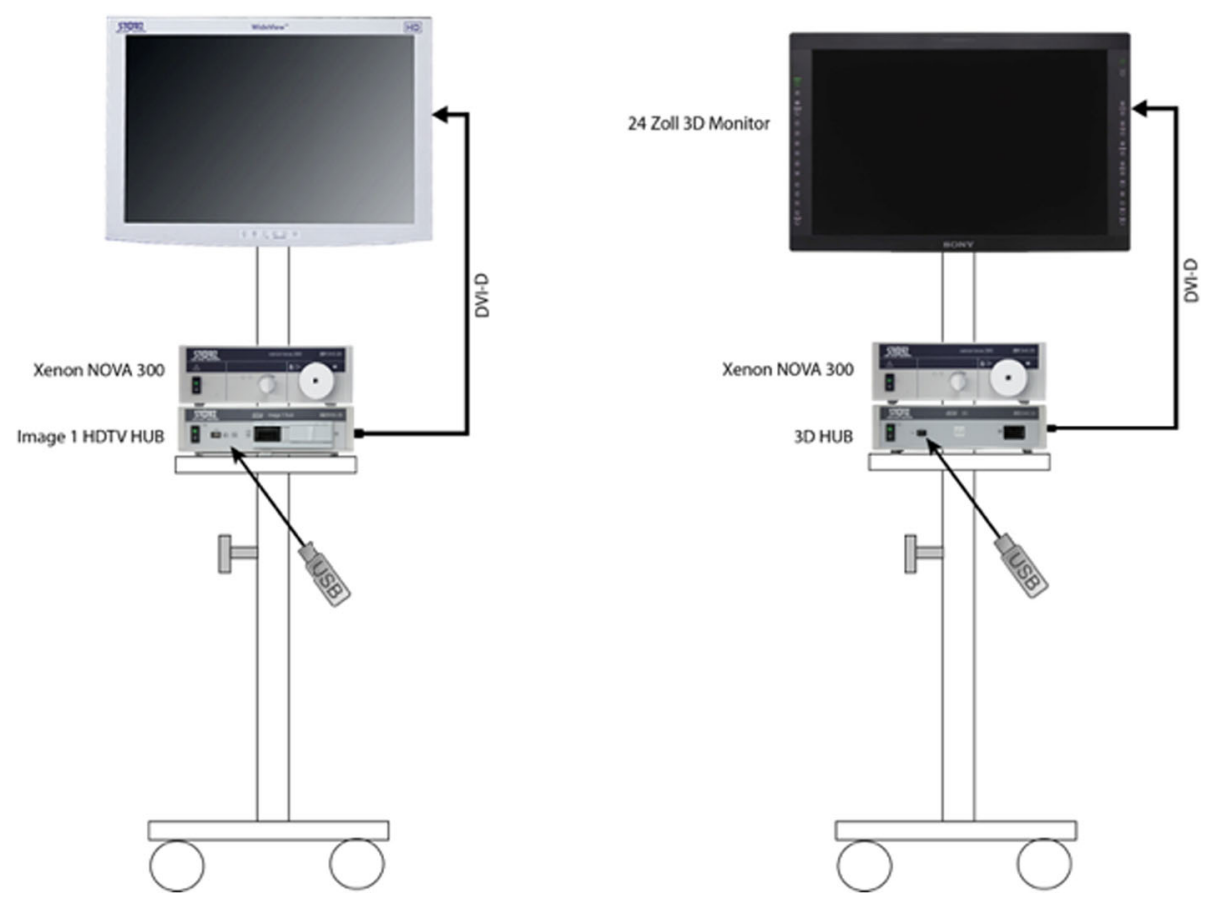

Fig. 2 Installation of the $2 D$ and $3 D$ systems 
equipped with a 24-in. monitor and a $300 \mathrm{~W}$ Xenon light source (Karl Storz SE \& Co., Tuttlingen, Germany). The camera control unit possessed a capacity for videos with a resolution up to $720 \mathrm{p}$.

For the 2D system, a Storz Hopkins II, $10 \mathrm{~mm}, 0^{\circ}$ telescope with a Xenon Nova 300 light source and an Image $1 \mathrm{H} 3-\mathrm{Z}$ Full HD camera (Karl Storz SE \& Co., Tuttlingen, Germany) was used. In practice, a $0^{\circ}$ optic is not standard anymore, as many surgeons use a $30^{\circ}$ optic. At the time this study was conducted, a 3D $30^{\circ}$ optic from Storz (Karl Storz SE \& Co., Tuttlingen, Germany) was unavailable. Therefore, a $0^{\circ}$ optic was used with the 2D system. The 3D system used a Storz 3D TIPCAMR1 with the same Xenon Nova 300 light source (Fig. 2).

\section{Instructions}

The study participants were given a written summary before completing the exercises. All of the details regarding the procedures were explained in short sentences.

Before each task, the participants viewed an introductory video, which included detailed explanations. If participants had any additional questions, they were given the opportunity to ask them prior to beginning the exercises.

\section{Exercises}

Tasks were designed to imitate real surgical scenarios, with the level of difficulty increasing from tasks 1 to 4. In order to measure the amount of time it took for each task to be completed, areas were highlighted to define the initial position of the laparoscopic instruments. Every task started and ended at this position. Errors were recorded and measured using an automatic fault counter for the objective evaluations of tasks 1,2 and 3. For these purpose the laparoscopic

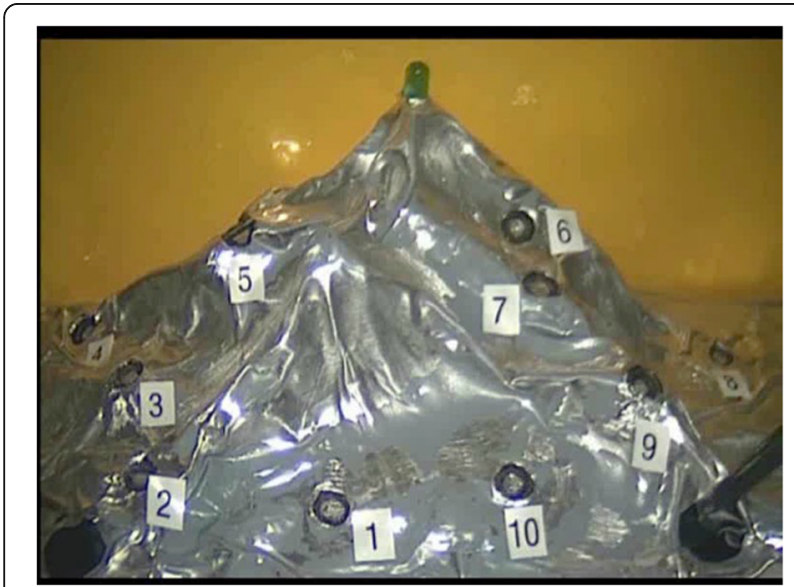

Fig. 3 Mountain relief

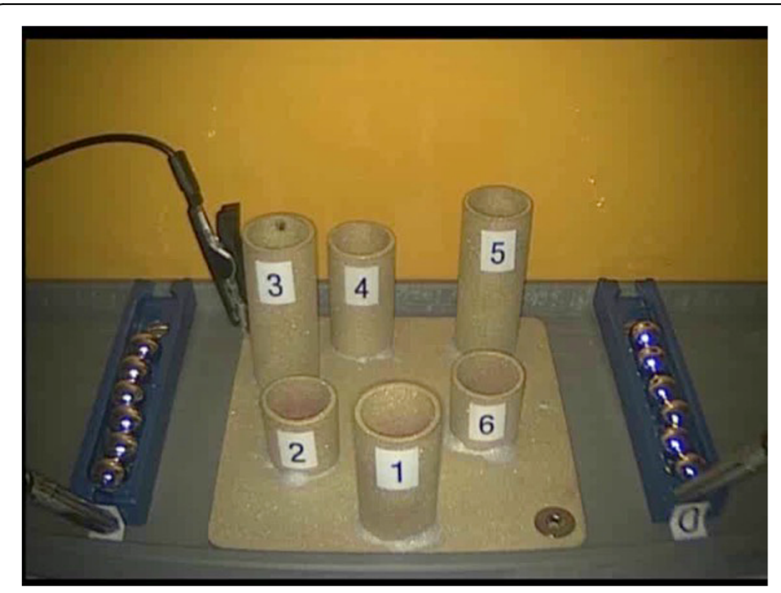

Fig. 4 Accuracy

clamps, as well as the area that was off-limits during the exercise, were connected to the counter. However, errors were manually counted for a subjective assessment in tasks 2 and 4. A digital clock with a start/ stop feature was used to record the time elapsed at the end of every task and measured the time required for each task to be completed.

Task 1 Mountain relief (orientation using $2 D$ and $3 D$ views) In this task, 10 numbered pins were positioned in a circle (Fig. 3). The goal of the task was to touch only the pins. When a pin was successfully contacted, it produced a light. The task began with the right-hand instrument making contact with pin number 1 and then continued in a clockwise direction. Once completed, the participant repeated the task with their left hand. Contacting the mountain in the wrong area or missing a pin was evaluated as a mistake. The participant was not informed of their mistakes during the task. A comparison between the $2 \mathrm{D}$ and $3 \mathrm{D}$ views is shown in Fig. 4.

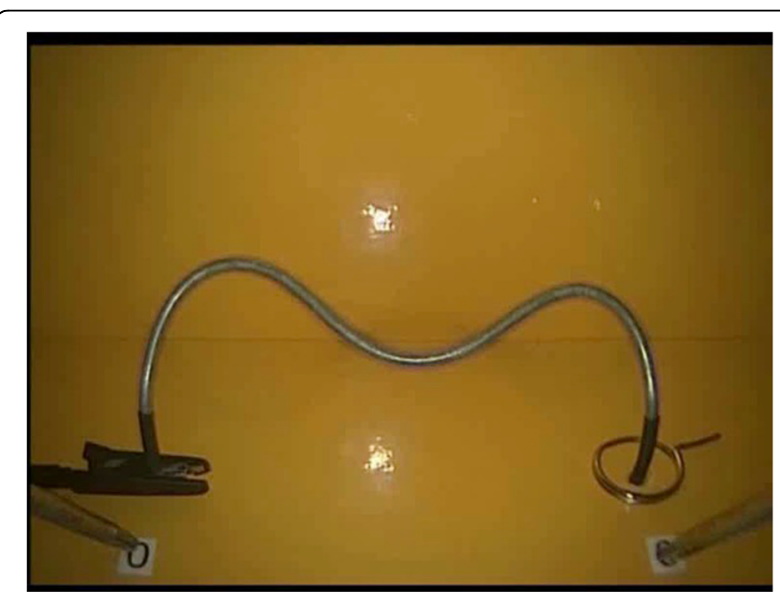

Fig. 5 Hot wire 


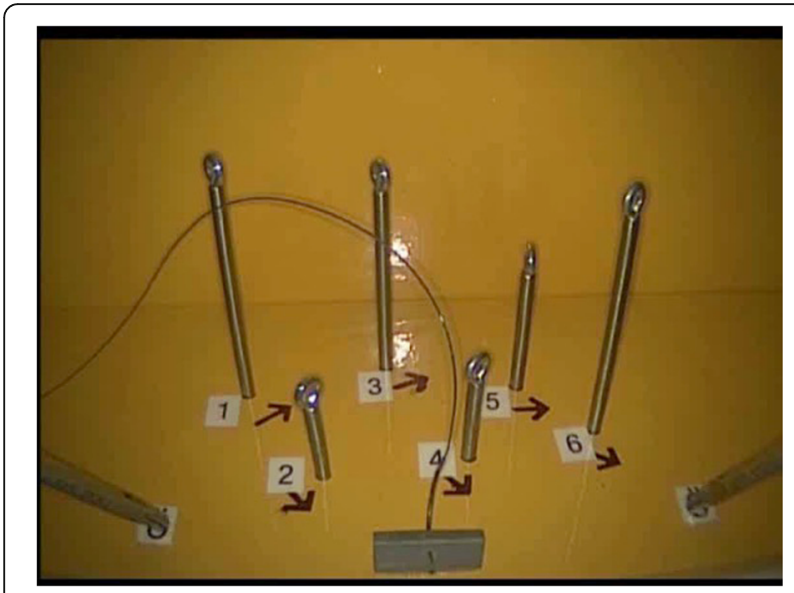

Fig. 6 Threading

Task two: Accuracy (Measuring precision in targeting defined points with movements of an object from $A$ to $B$ ) Six empty tubes were placed in a circle on a base plate with 2 ball containers holding 6 balls located on both the right and left sides of the tubes (Fig. 5). The goal of the task was to take the balls from the containers and place them inside the tubes without touching the tubes. After the start signal, the participant took the first ball from a container with the right-hand instrument and loaded tube number 1 . They continued with the other tubes in a clockwise direction. Once the right-hand side was completed, the participant completed the same task with the left-hand instrument. If a ball was dropped, it was abandoned and the participant continued with the next one. Touching the tubes or dropping a ball in the wrong tube or on the ground was recorded as a mistake.

Task three: Hot wire (Measuring accuracy, coordination and time for non-linear and continuous movements) A bent wire, insulated on both ends to rule out mistakes at the start, was attached to a base plate. A ring with an arm was threaded onto the wire (Fig. 6). The purpose of the task was to move the ring along the wire without making any contact. The participant started with the right-hand instrument and then switched to the left-hand one. Touching the wire with the ring was recorded as an error.

Task four: Threading (Measuring coordination with thread, needle and needle holder) Six eyelets were fixed to a base plate. All eyelets were numbered and labelled from left to right (Fig. 7). The goal of the task was to thread a V-Loc barbed suture through the first eyelet and then continue to do the same with the others, going from left to right. The participants were allowed to use either their right or left hand to control the needle. Skipping an eyelet, threading in the wrong order or direction, or accidental coiling of the suture were all counted as mistakes.

\section{Questionnaire}

After completing the exercises, participants answered a questionnaire regarding how they felt, both mentally and physically, about their experience using the $2 \mathrm{D}$ and $3 \mathrm{D}$ systems when completing the tasks.

\section{Statistical analysis}

To prevent selection bias, the order in which participants were given the 2D or 3D system was randomised. An Analysis of Variance with the SYSTAT Statistics software version 13 (Systat Software, San Jose, CA), was used to investigate the difference in means between groups A and B in terms of number of mistakes made and time to complete each of the tasks. Participants experience level, as well as the sequence and the dimensions (3D vs $2 \mathrm{D}$ ) were controlled for in the analyses. A $P$-value $<0.05$ was considered significant.

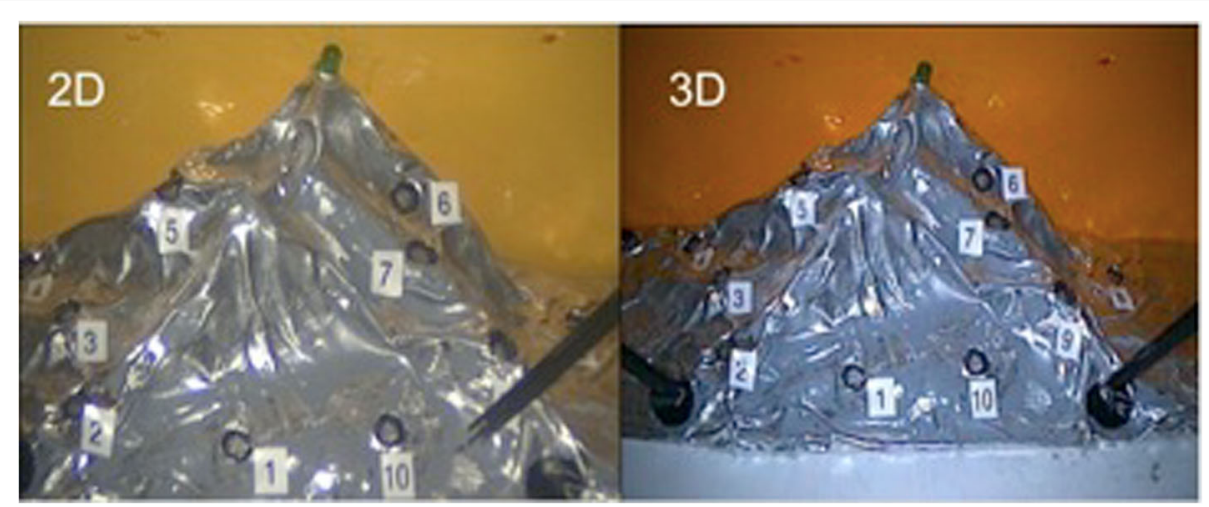

Fig. 7 Contrast between 2D and 3D view 
Table 1 Summary of task 1 results. Mean value (M) of the used time and mean value (M) of the mistakes made for the 2D and $3 \mathrm{D}$ system as well as the corresponding mean difference (MD) between the two systems. Additionally the correlating P-values for the difference in time and mistakes of the Group A and B put together

\begin{tabular}{|c|c|c|c|c|c|}
\hline & \multicolumn{2}{|l|}{ Group A } & \multicolumn{2}{|l|}{ Group B } \\
\hline & & Mistakes & Time(s) & Mistakes & Time(s) \\
\hline \multirow[t]{3}{*}{ Students } & M 2D & 28.55 & 146 & 46.00 & 173 \\
\hline & M 3D & 40.18 & 127 & 26.11 & 99 \\
\hline & MD 2D-3D & -11.64 & 19 & 19.89 & 74 \\
\hline \multirow[t]{3}{*}{ Non-experts } & M 2D & 34.18 & 104 & 32.75 & 96 \\
\hline & M 3D & 36.64 & 92 & 33.25 & 66 \\
\hline & MD 2D-3D & -2.45 & 12 & -0.50 & 30 \\
\hline \multirow[t]{4}{*}{ Experts } & M 2D & 24.33 & 88 & 23.00 & 113 \\
\hline & M 3D & 23.17 & 82 & 24.56 & 73 \\
\hline & MD 2D-3D & 1.17 & 6 & -1.56 & 40 \\
\hline & $P$-value & \multicolumn{2}{|c|}{$\begin{array}{l}\text { Mistakes Group A + B } \\
0.0076\end{array}$} & \multicolumn{2}{|c|}{$\begin{array}{l}\text { Time Group A + B } \\
0.0001\end{array}$} \\
\hline
\end{tabular}

\section{Results}

\section{Task 1: Mountain relief}

Overall, the participants performed significantly faster $(P=0.0001)$ and made fewer mistakes $(P=0.007)$ with the 3D system. All experience groups spent less time when using the $3 \mathrm{D}$ system. The students made fewer mistakes with the system they used in the second round, regardless of the system used in the first round.

The error ratio in the non-expert group was smaller when using the $2 \mathrm{D}$ system compared to the $3 \mathrm{D}$ one; hence, the type of system had an effect on the number of errors made while performing the tasks. The experts produced fewer mistakes with the system they used first, no matter which system was used (Table 1).

\section{Task 2: accuracy}

Participants required significantly less time $(P=0.004)$ for this task, although, there was no significant difference in the mistakes made between groups A and B.

The students and non-experts required less time for the second task no matter which system was used. Experts spent less time when using the 3D system (Table 2).

\section{Task 3: hot wire}

Performance results for all experience groups showed a significant reduction in time spent completing this task $(P=0.0001)$ and mistakes made $(P=0.007)$.

The students performed the second round more quickly and with fewer mistakes, and the type of system used had no effects. In contrast, the 3D system helped the experts and non-experts reduce their errors (Table 3).

\section{Task 4: threading}

All experience groups showed a significant decrease in time spent completing this task $(\mathrm{P}=0.007)$ when using the 3D system; although, there were no significant reductions in the number of mistakes made $(P=0.488)$. Group B students took nearly twice as long as Group A with the 2D technique. In the other two experience groups, namely non-experts and experts the time difference was smaller, but still significant (Table 4).

Table 2 Summary of task 2 results. Mean value (M) of the used time and mean value (M) of the mistakes made (a=automatically measured and $m=$ manually measured) for the $2 \mathrm{D}$ and $3 \mathrm{D}$ system as well as the corresponding mean difference (MD) between the two systems. Additionally the correlating $P$-values for the difference in time and mistakes of the Group A and B put together

\begin{tabular}{|c|c|c|c|c|c|c|c|}
\hline & & \multicolumn{3}{|l|}{ Group A } & \multicolumn{3}{|l|}{ Group B } \\
\hline & & $\begin{array}{l}\text { Mistakes } \\
\text { (a) }\end{array}$ & Mistakes (m) & $\begin{array}{l}\text { Time } \\
\text { (s) }\end{array}$ & Mistakes (a) & Mistakes (m) & $\begin{array}{l}\text { Time } \\
\text { (s) }\end{array}$ \\
\hline \multirow[t]{3}{*}{ Student } & M 2D & 1.91 & 5.45 & 137 & 4.22 & 6.00 & 162 \\
\hline & M 3D & 3.91 & 2.27 & 159 & 2.89 & 2.56 & 135 \\
\hline & MD 2D-3D & -2.00 & 3.18 & -22 & 1.33 & 3.44 & 27 \\
\hline \multirow[t]{3}{*}{ Non-experts } & M 2D & 4.30 & 4.82 & 100 & 1.00 & 4.75 & 90 \\
\hline & M 3D & 3.36 & 2.64 & 106 & 3.00 & 2.50 & 83 \\
\hline & MD 2D-3D & 0.94 & 2.18 & -5 & -2.00 & 2.25 & 7 \\
\hline \multirow[t]{4}{*}{ Experts } & M 2D & 10.00 & 4.17 & 81 & 5.88 & 4.44 & 101 \\
\hline & M 3D & 2.50 & 2.20 & 79 & 2.00 & 0.88 & 80 \\
\hline & MD 2D-3D & 7.50 & 1.97 & 2 & 3.88 & 3.57 & 21 \\
\hline & $P$-value & \multicolumn{2}{|c|}{$\begin{array}{l}\text { Mistakes Group A + B } \\
0.7902\end{array}$} & \multicolumn{2}{|c|}{$\begin{array}{l}\text { Mistakes Group A + B } \\
0.6275\end{array}$} & \multicolumn{2}{|c|}{$\begin{array}{l}\text { Time Group A + B } \\
0.0041\end{array}$} \\
\hline
\end{tabular}


Table 3 Summary of task 3 results. Mean value (M) of the used time and mean value (M) of the mistakes made for the 2D and 3D system as well as the corresponding mean difference (MD) between the two systems. Additionally the correlating $P$-values for the difference in time and mistakes of the Group A and B put together

\begin{tabular}{|c|c|c|c|c|c|}
\hline & & \multicolumn{2}{|l|}{ Group A } & \multicolumn{2}{|l|}{ Group B } \\
\hline & & Mistakes & Time(s) & Mistakes & Time(s) \\
\hline \multirow[t]{3}{*}{ Students } & M 2D & 53.82 & 151 & 72.67 & 205 \\
\hline & M 3D & 70.00 & 207 & 40.11 & 149 \\
\hline & MD 2D-3D & -16.18 & -56 & 32.56 & 56 \\
\hline \multirow[t]{3}{*}{ Non-experts } & M 2D & 44.18 & 113 & 39.75 & 114 \\
\hline & M 3D & 29.55 & 138 & 18.00 & 95 \\
\hline & MD 2D-3D & 14.64 & -25 & 21.75 & 19 \\
\hline \multirow[t]{4}{*}{ Experts } & M 2D & 40.83 & 105 & 44.89 & 127 \\
\hline & M 3D & 25.33 & 99 & 34.67 & 97 \\
\hline & MD 2D-3D & 15.50 & 6 & 10.22 & 30 \\
\hline & $P$-value & \multicolumn{2}{|c|}{$\begin{array}{l}\text { Mistakes Group A + B } \\
0.0074\end{array}$} & \multicolumn{2}{|c|}{$\begin{array}{l}\text { Time Group A + B } \\
0.0001\end{array}$} \\
\hline
\end{tabular}

\section{Questionnaire results}

Participants rated all of the tasks as more challenging when using the 2D system. Furthermore, participants found that they became accustomed to the 2D system after a single task. In contrast, it took two tasks before subjects were accustomed to the 3D system (Figs. 8 and 9).

Seventy-two percent of the participants reported no lessening of concentration when using the 3D system, while $66 \%$ reported no difficulty concentrating when using the $2 \mathrm{D}$ system. In addition, only two subjects reported feelings of nausea and dizziness while using the $3 \mathrm{D}$ system. There was no nausea or vertigo in $96 \%$ of the subjects (Figs. 10 and 11).
When asked if they felt handicapped by the 3D glasses, five participants found the eyewear to be irritating. The reasons given included the glasses fogging-up with movement and losing the 3D view when turning the head sideways. However, more than $90 \%$ of subjects considered the 3D system to be more beneficial than the $2 \mathrm{D}$ system (Figs. 12 and 13).

\section{Discussion}

The expected advantages of the 3D system include an improved learning curve with greater speed, optimised precision and fewer mistakes that result in shorter operation times, fewer complications and cost reduction.

Table 4 Summary of task 4 results. Mean value (M) of the used time and mean value (M) of the mistakes made for the 2D and 3D system as well as the corresponding mean difference (MD) between the two systems. Additionally the correlating P-values for the difference in time and mistakes of the Group A and B put together

\begin{tabular}{|c|c|c|c|c|c|}
\hline & & \multicolumn{2}{|l|}{ Group A } & \multicolumn{2}{|l|}{ Group B } \\
\hline & & Mistakes & Time(s) & Mistakes & Time(s) \\
\hline \multirow[t]{3}{*}{ Students } & M 2D & 0.18 & 421 & 0.00 & 545 \\
\hline & M 3D & 0.18 & 406 & 0.00 & 283 \\
\hline & MD 2D-3D & 0.00 & 15 & 0.00 & 262 \\
\hline \multirow[t]{3}{*}{ Non-experts } & M 2D & 0.27 & 330 & 0.00 & 281 \\
\hline & M 3D & 0.00 & 282 & 0.00 & 171 \\
\hline & MD 2D-3D & 0.27 & 48 & 0.00 & 110 \\
\hline \multirow[t]{4}{*}{ Experts } & M 2D & 0.00 & 181 & 0.00 & 192 \\
\hline & M 3D & 0.00 & 160 & 0.00 & 132 \\
\hline & MD 2D-3D & 0.00 & 21 & 0.00 & 60 \\
\hline & $P$-value & \multicolumn{2}{|c|}{$\begin{array}{l}\text { Mistakes Group A + B } \\
0.4887\end{array}$} & \multicolumn{2}{|c|}{$\begin{array}{l}\text { Time Group A + B } \\
0.0073\end{array}$} \\
\hline
\end{tabular}




\section{How challenging were the tasks on a scale of 1 to 5 ?}

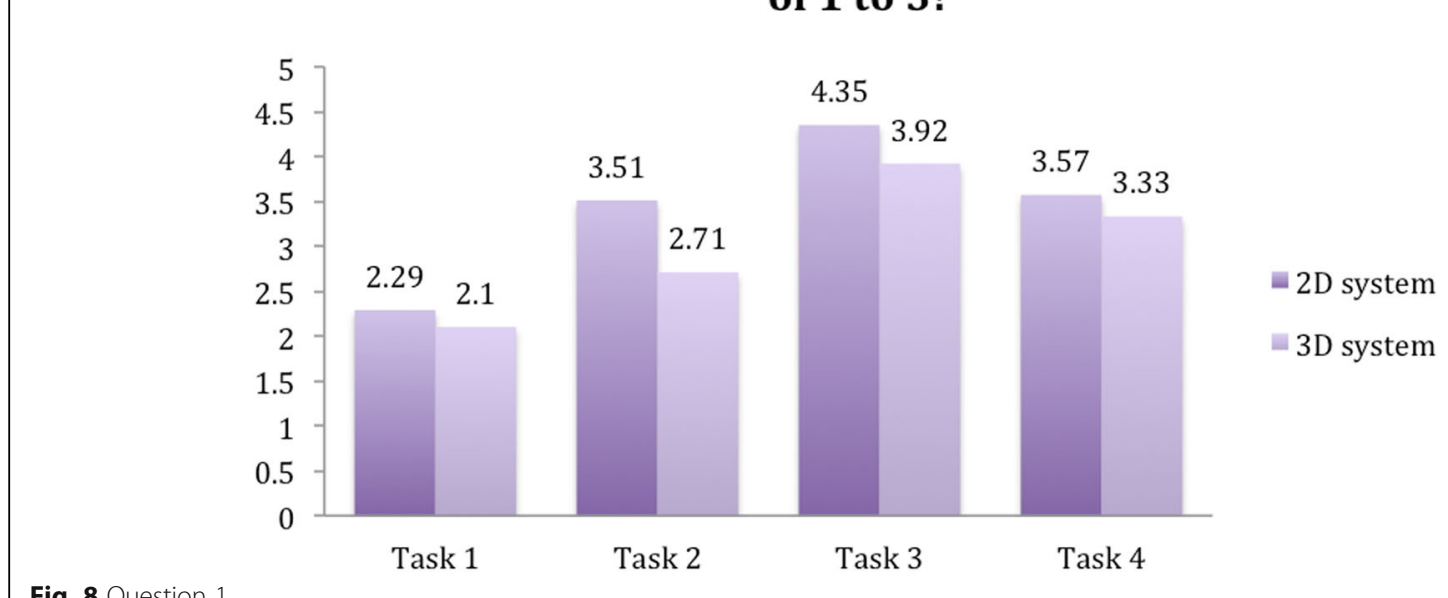

Fig. 8 Question 1

There was no difference regarding the sequence in which the systems were used, and in all tasks the expert group was significantly faster than the student and nonexpert groups.

We anticipated that the 3D system would have a distinct advantage for all of the groups and tasks. Overall, a reduction in mistakes and time was achieved. Group B performed $20 \%$ faster, on average, during all 4 tasks and made fewer mistakes in 2 of the tasks compared to group A. The experts significantly benefited from the 3D system in terms of accuracy when performing the ballthrowing exercise compared to the non-experts and students (Table 2). The students, however, showed a significantly greater benefit when using the 3D system in terms of less accidental contact in comparison to experts and non-experts when performing task 3 (Table 3). All participants rated the 3D tasks as easier to perform; and, this rating was significant for the first 3 tasks. The number of tasks that were needed before the candidates adjusted to the perspective did not differ between the 2D and 3D systems. Loss of concentration occurred at the same rate and after the same amount of time for both systems as well. Nausea and dizziness were reported only when working with the $3 \mathrm{D}$ system. As a result of the learning effect, the participants performed the second round of trials better than the first round. This effect was especially evident in the beginners, suggestive of a novelty effect, as the more experienced the candidates were, the smaller the effect of the 3D system. According to the subjects' perceptions, the 3D system gave them an advantage. Nearly $100 \%$ of the subjects considered the 3D system as beneficial, with disadvantages, as nausea

\section{After which task have you become accustomed to the system?}

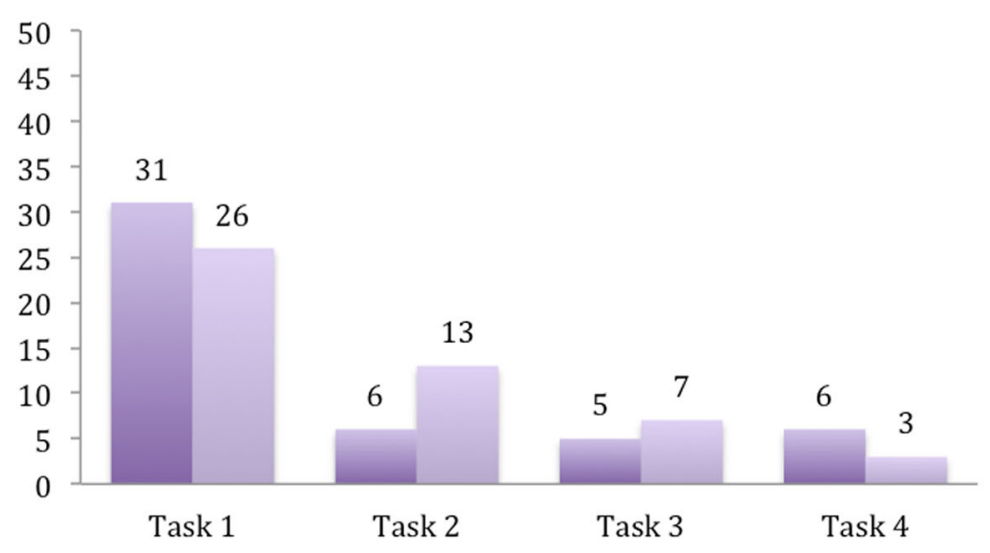

Fig. 9 Question 2 


\section{Did you lose your concentration during the tasks?}

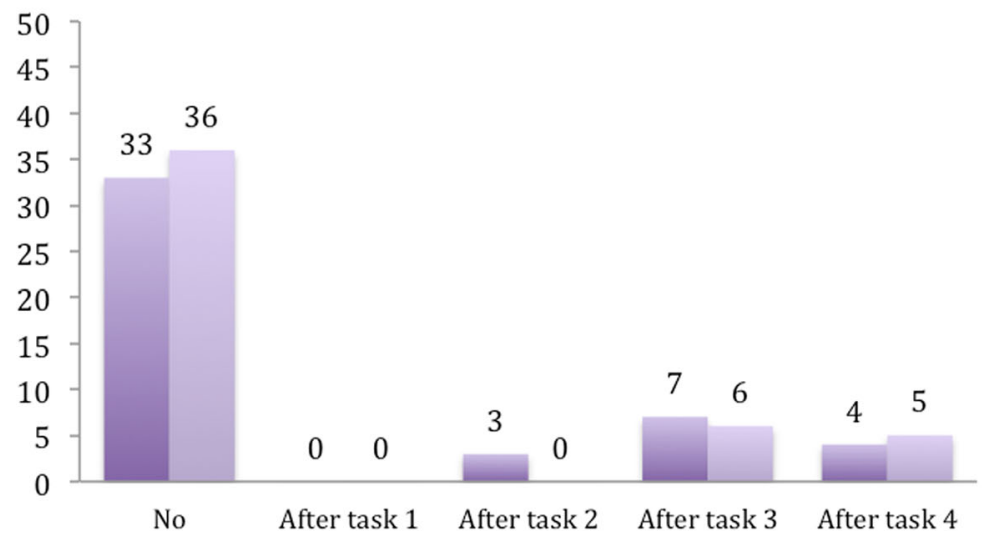

Fig. 10 Question 3

and dizziness or handicapped by the 3D glasses because of the glasses fogging-up with movement and losing the $3 \mathrm{D}$ view when turning the head sideways, noticed only occasionally.

This work supports previous studies investigating the benefits of this technology and explains the disadvantages in detail, such as the hindrance experienced when using goggles, loss of concentration and headache [710]. Measurements were also taken from non-experts. Doctors-in-training have not previously participated in research measuring the benefits of 3D. Their inclusion is another factor that suggests the 3D technique can be easily incorporated into routine LSCs, which are currently an important aspect of modern surgery [11-13]. There are examples of robot-assisted LSCs, such as the Da Vinci, which benefits from 3D visualization and increased degrees of freedom to provide better results $[14,15]$. However, the combination of $3 \mathrm{D}$ and conventional LSC offers a more cost-effective and simpler alternative to the Da Vinci $[16,17]$. Yet, this technology is still in the developmental phase, thus our work should be seen as a contribution to help move this technology forward [11, 18-20].

However, there is room for improvements in future projects. The major limitation of this study is that a $0^{\circ}$ optic was used with the $2 \mathrm{D}$ system as a $3 \mathrm{D} 30^{\circ}$ optic from Storz (Karl Storz SE \& Co., Tuttlingen, Germany) was unavailable at the time this study was conducted. Using a $0^{\circ}$ optic is not standard anymore, thus, some of the experts or non-experts may have experienced issues with the unusual perspective and this could have affected the performance with the $2 \mathrm{D}$ system. Then again,

\section{Did the tasks trigger nausea or vertigo?}

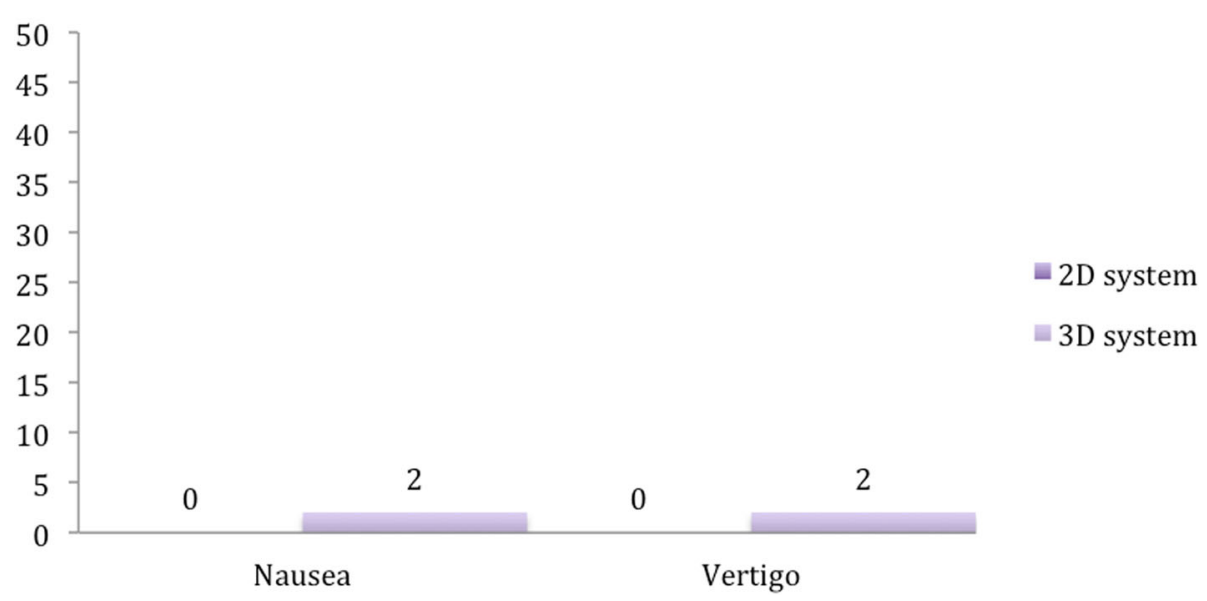

Fig. 11 Question 4 


\section{Did the eyewear obstruct performing the tasks?}

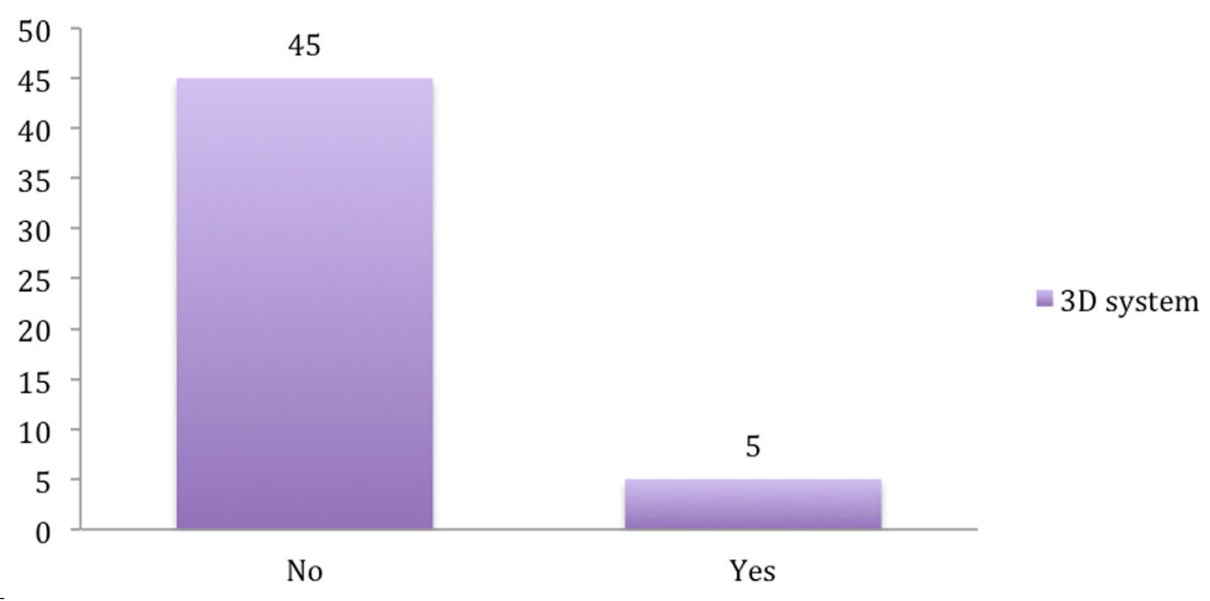

Fig. 12 Question 5

all the participants performed the exercises under the same conditions. The second limitation of this study is that the number of participants is small. This is partly the result of the strict inclusion criteria for the experts and then again due to the difficulty of recruiting nonexperts. Though, compared to other comparative studies exploring the role of the $3 \mathrm{D}$ and $2 \mathrm{D}$ system in laparoscopy the recruited number of participants is similar [2123]. The third limitation of the current study is the challenging interpretation of the results on the basis of the inhomogeneous composition of the two groups as a result of the conducted randomization. The candidates were randomized in order to prevent a selection bias. The initial randomization proved to be correct. There was no difference regarding the sequence in which the systems were used and no difference of the performance could be detected if you look at the same experience level in the respective groups. However, a crossover study without this type of randomization could be more suitable for a comparative pelvitrainer study [22-24].

In summary this study suggests, surgeons should start using 3D systems early in their operating career, as the effects are substantial for beginners and the learning curve can be improved. This is especially important as there are fewer operations due to an increase in the number of conservative procedures based on better alternative treatments or diagnostics [25-30]. In some clinics, the 3D system is available in the operation theatre as a permanent feature, but is rarely used. This could be also an approach that may prove useful in increasing the use of robot-assisted LSC using simple tools. A multi-centre study comparing the outcome of

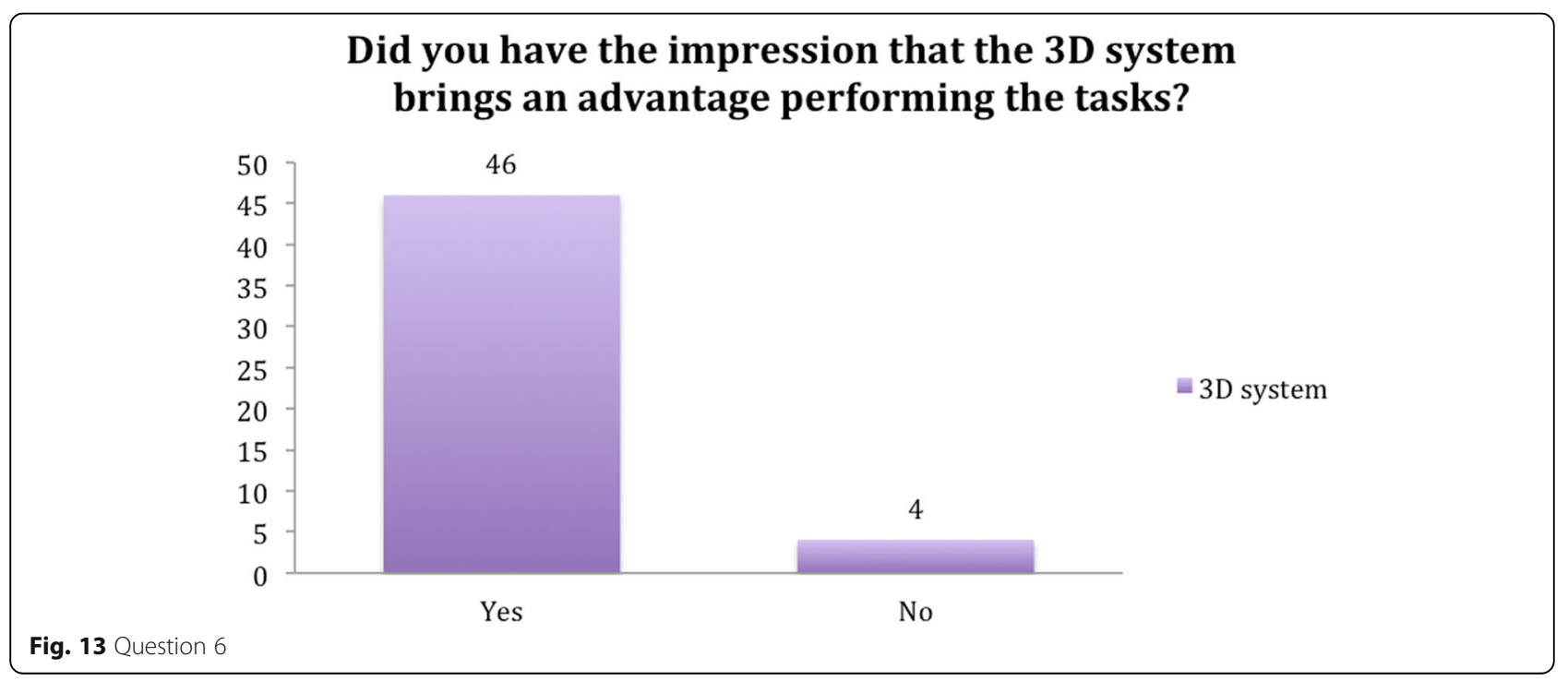


operations using 3D systems in conventional LSC and robot-assisted LSC should be considered for future studies.

\section{Conclusion}

Irrespective of experience level, 3D laparoscopy shows advantages in saving time, increasing accuracy and reducing mistakes. These benefits were also accompanied by subjective advantages that were noted by the participants. However, the more complex the task, the less significant the benefit of the 3D system and some people feel handicapped by the eyewear.

\section{Abbreviations}

3D: 3 dimensional; 2D: 2 dimensional; LSC: Laparoscopy; IRB: Institutional review board; HD: High definition

\section{Acknowledgements}

Not applicable.

\section{Authors' contributions}

(I) Conception and design: DL, BF, MM. (II) Administrative support: MM, BF. (III) Provision of study materials or patients: MM, BF, DL. (IV) Collection and assembly of data: DL. (V) Data analysis and interpretation: TZ, DL. (VI) Manuscript writing: All authors. (VII) Final approval of manuscript: All authors.

\section{Funding}

Not applicable.

\section{Availability of data and materials}

The datasets analysed during the current study are available from the corresponding author on reasonable request.

\section{Ethics approval and consent to participate}

According to the ethics committee Northwest and Central Switzerland (EKNZ) the project does not fall under the remit of the cantonal or federal law HRA (Human Research Act) because the project is not defined as a research project as per Human Research Act Art. 2; therefore, an IRB approval is not needed. All participants had to give their written consent to participate in this study and waive any claims. The anonymisation of personal data was guaranteed.

\section{Consent for publication}

Not applicable.

\section{Competing interests}

The authors Tibor Andrea Zwimpfer, Dominik Lacher, Bernhard FellmannFischer and Michael Mueller have no competing interest to disclose.

\section{Author details}

${ }^{1}$ University Hospital Basel, Gynecological Clinic, Basel, Switzerland. ${ }^{2}$ Hospital Limmattal, Zürich, Switzerland. ${ }^{3}$ University Hospital Berne, Gynecological Clinic, Berne, Switzerland.

\section{Received: 5 May 2020 Accepted: 28 September 2020}

Published online: 09 November 2020

\section{References}

1. Cerdan Santacruz C, Frasson M, Flor-Lorente B, Ramos Rodriguez JL, Trallero Anoro M, Millan Scheiding M, Maseda Diaz O, Dujovne Lindenbaum P, Monzon Abad A, Garcia-Granero Ximenez E. Laparoscopy may decrease morbidity and length of stay after elective colon cancer resection, especially in frail patients: results from an observational real-life study. Surg Endosc. 2017. https://doi.org/10.1007/s00464-017-5548-3 Apr 18, 2017.

2. Keller DS, Delaney CP, Hashemi L, Haas EM. A national evaluation of clinical and economic outcomes in open versus laparoscopic colorectal surgery. Surg Endosc. 2016;30(10):4220-8.
3. He HY, Yang ZJ, Zeng DY, Yao DS, Fan JT, Zhao RF, Zang JQ, Hu XX, Lin Z, Jiang YM, Li L. Comparison of the short-term and long-term outcomes of laparoscopic surgery and open surgery for early-stage cervical cancer. Zhonghua Zhong Liu Za Zhi. 2017:39(6):458-66.

4. Park JY, Kim DY, Kim JH, Kim YM, Kim YT, Nam JH. Laparoscopic versus open radical hysterectomy for elderly patients with early-stage cervical cancer. Am J Obstet Gynecol. 2012;207(3):195-8.

5. Perez-Duarte FJ, Sanchez-Margallo FM, Diaz-Guemes Martin-Portugues I. Ergonomics in laparoscopic surgery and its importance in surgical training. Cir Esp. 2011;90(5):284-91.

6. Zeng Q, Lei F, Gao Z, Wang Y, Gao QK. Case-matched study of short-term effects of 3D vs 2D laparoscopic radical resection of rectal cancer. World J Surg Oncol. 2007;15:178.

7. Leon P, Rivellini R, Giudici F, Sciuto A, Pirozzi F, Corcioni F. 3D vision provides shorter operative time and more accurate intraoperative surgical performance in laparoscopic hiatal hernia repair compared with 2D vision. Surg Innov. 2017;24(20):155-61

8. Kim S, May A, Ryan H, Mohsin A, Tsuda S. Distraction and proficiency in laparoscopy: 2D versus robotic console 3D immersion. Surg Endosc. 2017; 31(11):4625-30.

9. Nishi M, Kanaji S, Otake Y, Harada H, Yamamoto M, Oshikiri T, Nakamura T, Suzuki S, Suzuki Y, Hiasa Y, Sato Y, Kakeji Y. Quantitative comparison of operative skill using 2- and 3-dimensional monitors during laparoscopic phantom tasks. Surgery. 2017;161(5):1334-40.

10. Hagelsteen K, Langegard A, Lantz A, Ekelund M, Anderberg M, Bergenfelz A. Faster acquisition of laparoscopic skills in virtual reality with haptic feedback and 3D vision. Minim Invasive Ther Allied Technol. 2017;26(5):269-77.

11. Schwab K, Smith R, Brown V, Whyte M, Jourdan I. Evolution of stereoscopic imaging in surgery and recent advances. World J Gastrointest Endosc. 2017;9(8):368-77.

12. Mettler L, Sammur W, Alkatout I, Schollmeyer T. Imaging in gynecologic surgery. Womens Health (Lond). 2011;7(2):239-48.

13. Sarli L, Pietra N, Carreras F, Longinotti E, Peracchia A. Today's treatment of cholelithiasis: laparoscopic surgery. Acta Biomed Ateneo Parmense. 1992; 63(1-2):59-67.

14. D'Annibale A, Morpurgo E, Fiscon V, Trevisan P, Sovernigo G, Orsini C, Guidolin D. Robotic and laparoscopic surgery for treatment of colorectal diseases. Dis Colon rectum. 2004;47(12):2162-8.

15. Choussein S, Srouji SS, Farland LV, Wietsma A, Missmer SA, Hollis M, Yu RN, Pozner CN, Gargiulo AR. Robotic assistance confers ambidexterity to laparoscopic surgeons. J Minim Invasive Gynecol. 2018;25(1):76-83.

16. El Hachem L, Andikyan V, Matthews S, Friedman K, Poeran J, Shiek K, Geoghegan M, Gretz HF. Robotic single-site and conventional laparascopic surgery in gynecology: Clinal outcomes and cost analysis of a matched case-control study. J Minim Invasive Gynecol. 2016;23(5):760-8.

17. Marino P, Houvenaeghel G, Narducci F, Boyer-Chammard A, Ferron G, Uzan C, Bats AS, Mathevet P, Dessogne P, Guyon F, Rouanet P, Jaffe I, Carcopino $X$, Perez T, Lambaudie E. Cost-effectiveness of conventional vs roboticassisted laparoscopy in gynecologic oncologic indications. Int J Gynecol Cancer. 2015;25(6):1102-8.

18. Sakata S, Watson MO, Grove PM, Stevenson AR. The conflicting evidence of three-dimensional displays in laparoscopy: a review of systems old and new. Ann Surg. 2016;263(2):234-9.

19. Voges U. Laparoscopic technique--which developments are possible? Urologe A. 1996;35(3):208-14.

20. Nicklin J. The future of robotic-assisted laparoscopic gynaecologic surgery in Australia - a time and a place for everything. Aust N Z J Obstet Gynaecol. 2017;57(5):493-8.

21. Peitgen K, Walz V, Walz M, Holtmann G, Eigler F. A prospective randomized experimental evaluation of three-dimensional imaging in laparoscopy. Gastrointest Endosc. 1996;44(3):262-7.

22. Gomez-Gomez E, Carrasco-Valiente J, Valero-Rosa J, Campos-Hernandez JP, Anglada-Curado FJ, Carazo-Carazo JL, Font-Ugalde P, Requena-Tapia MJ. Impact of 3D vision on mental workload and laparoscopic performance in inexperienced subjects. Actas Urol Esp. 2015;39(4):229-35.

23. Votanopoulos K, Brunicardi FC, Thornby J, et al. Impact of three-dimensional vision in laparoscopic training. World J Surg. 2008:32:110-8.

24. Zwimpfer TA, Fellmann-Fischer B, Oehler R, Schötzau A, Kind AB. A crossover study on the advantage of an additional rotation function in a needle holder compared to a conventional needle holder in a pelvitrainer model. Laparosc Surg. 2020. https://doi.org/10.21037//s. 2019.11.03. 
25. Jacobson GF, Shaber RE, Armstrong MA, Hung YY. Changes in rates of hysterectomy and uterine conserving procedures for treatment of uterine leiomyoma. Am J Obstet Gynecol. 2007;196(6):601.

26. Solnik MJ, Munro MG. Indications and alternatives to hysterectomy. Clin Obstet Gynecol. 2014;57(1):14-42.

27. Yusef F, Leeder S, Wilson A. Recent estimates of the incidence of hysterectomy in New South Wales and trends over the past 30 years. Aust N Z J Obstet Gynaecol. 2016;56(4):420-5.

28. Parazzini F, Ricci E, Bulfoni G, Cipriani S, Chiaffarino F, Malvezzi M, Frigerio L. Hysterectomy rates for benign conditions are declining in Lombardy, Italy: 1996-2010. Eur J Obstet Gynecol Reprod Biol. 2014;178:107-13.

29. Podda M, Gerardi C, Cillara N, Fearnhead N, Gomes CA, Birindelli A, Mulliri A, Davies RJ, Di Saverio S. Antibiotic treatment and appendectomy for uncomplicated acute appendicitis in adults and children: a systematic review and meta-analysis. Ann Surg. 2019. https://doi.org/10.1097/ SLA0000000000003225 January 31, 2019.

30. Salminen P, Paajanen H, Rautio T, Nordström P, Aarnio M, Rantanen T, Tuominen R, Hurme S, Virtanen J, Mecklin JP, Sand J, Jartti A, Rinta-Kiikka I, Grönroos JM. Antibiotic therapy vs appendectomy for treatment of uncomplicated acute appendicitis: the APPAC randomized clinical trial. JAMA. 2015;313(23):2340-8.

\section{Publisher's Note}

Springer Nature remains neutral with regard to jurisdictional claims in published maps and institutional affiliations.

Ready to submit your research? Choose BMC and benefit from:

- fast, convenient online submission

- thorough peer review by experienced researchers in your field

- rapid publication on acceptance

- support for research data, including large and complex data types

- gold Open Access which fosters wider collaboration and increased citations

- maximum visibility for your research: over $100 \mathrm{M}$ website views per year

At BMC, research is always in progress.

Learn more biomedcentral.com/submissions 